\title{
rParasitic Liver Abscess Caused By Ascaris Lumbricoides - A Case Report
}

\author{
*S M Khodeza Nahar Begum, Quazi Tarikul Islam \\ Dr S M Khodeza Nahar Begum \\ Associate Professor of Pathology; Anwer Khan Modern Medical College, Dhaka \\ Prof Dr Quazi Tarikul Islam \\ Professor of Medicine, Dhaka Medical College, Dhaka
}

*Corresponding Author

\begin{abstract}
This is a case report of a middle aged man who presented with weight loss and epigastric pain. The initial diagnosis was space occupying lesion in liver. The mass was later demonstrated by trans-abdominal percutaneous needle biopsy to be an abscess caused by Ascaris lumbricoides. Fertilized Eggs and Larvae of Ascaris lumbricoides was found.
\end{abstract}

Key Words: Liver Abscess, Ascaris Lumbricoides

\section{Introduction}

Ascaris lumbricoides is distributed widely in tropical and subtropical areas, especially in the developing countries of South America, Africa, and Asia. More than one billion infections are estimated to exist at any given time. In rural areas of Asia, it is not unusual to find 85 percent of the population passing Ascaris eggs ${ }^{1}$. Some people appear to be predisposed to infection with $A$. lumbricoides. Some individuals are found to be constantly infected and usually have a higher intensity of infections than others.

These individuals become sensitized, and migrating larvae may cause tissue reactions in the Liver and Lungs, with eosinophilic infiltration and granuloma formation. Ascariasis of the Liver can also be caused by adult worms and eggs located in the bile ducts or in the liver parenchyma. Rarely, the adult parasite may die inside the Liver, giving rise to a necrotic focus ${ }^{2}$.

\section{Case Report}

A 50-year-old man (Fig-1), coming from the rural area of Shirajgonj district, Bangladesh, was referred to the govt. Hospital of Rajshahi district because of a mass in the right lobe of the liver. $\mathrm{He}$ had a history of a chronic illness of six months duration characterized with weight loss, cough, constipation and abdominal pain in the upper right zone. Ultrasound study revealed an irregular outlined hypo echoic lesion, about $6 \mathrm{~cm}$ in diameter, located in the extreme superior aspect of the lateral aspect of right lobe (Fig-2). The liver was however not enlarged. Chest skiagram revealed mild degree of right sided pleural effusion.

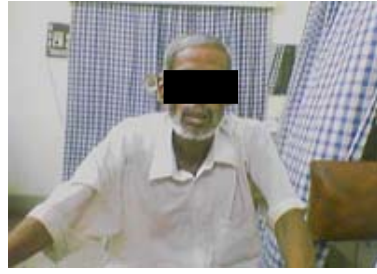

Fig 1: The Patient

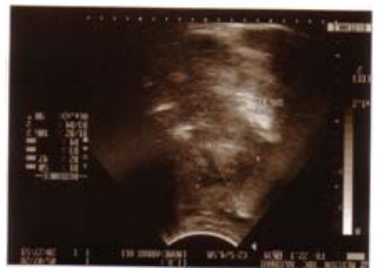

Fig 2: Ultrasonograph of Liver
Upon admittance he had fibrile peaks of upto $100^{\circ}$ F. With tachycardia. He appeared severely anaemic, no visceral enlargement was found but tenderness was detected in right hypochondriac region of abdomen.

The laboratory results were as follows: $\mathrm{Hb}: 5.8$ $\mathrm{g} / \mathrm{dl}$, erythrocyte sedimentation rate: $130 \mathrm{~mm}$ in the first 1 hour, leukocyte count: 10,500/ml, neutrophils: $67 \%$, lymphocytes $20 \%$, monocytes $2 \%$, eosinophils: $11 \%$; Widal test titre was within normal limit, DAT for Kala-azar was negative. Total bilirubin $0.7 \mathrm{mg} / \mathrm{dl}$; direct bilirubin: 0.2 $\mathrm{mg} / \mathrm{dl}$. AST: 38 IU/L, ALT: 41 IU/L, alkaline phosphatase $102 \mathrm{mg} / \mathrm{dl}$. Stool examination revealed occasional ova of Ascaris Lumbricoides. Kidney function tests were normal. The hepatic lesion was punctured and biopsied under ultrasonographic observation. Approximately $10 \mathrm{ml}$ of purulent 
material was obtained. Upon direct examination, fertilized eggs and larvae of Ascaris lumbricoides were found (Fig. 3,4). Gram stained smears revealed scarce Gram-positive cocci with intense neutrophilic reaction. Culture and sensitivity of the aspirated fluid yielded growth of Staphylococcus aureus. Mebendazole as well as a Cephalosporin preparation was prescribed and the patient became reasonably well. Check Ultrasonogram after 6 wks. Revealed a heterogeneous alteration (suggesting a healing lesion) but no mass or liquid collection was seen.
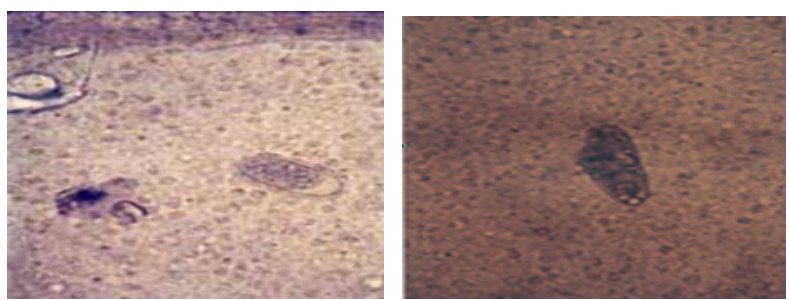

Fig 3: Fertilized ova

Fig 4: Larvae of A Lumbricoides

\section{Discussion}

Liver abscess caused by Ascaris Lumbricoides has no distinctive clinical features to allow its differential diagnosis with Liver abscesses caused by other microorganisms ${ }^{3}$. Most of the cases reported so far have been diagnosed during surgery or during autopsy. The specific diagnosis of Ascaris in Liver is established by the observation of eggs on direct or histological examination. The diagnosis of liver abscess can be suspected clinically, but to confirm it and to determine its etiology several investigations are needed including chest X-ray, ultrasound study, immunodiagnostic tests, microbiological tests and direct microscopic examination. Ultrasound is the most frequently used imaging study. CT scan and magnetic resonance are less frequently employed. However, the demonstration of the etiologic agent must always be sought ${ }^{4,5}$.

Percutaneous needle aspiration guided by either ultrasound or CT scan is indicated only for therapeutic and diagnostic purposes in order to identify the etiological agent ${ }^{6,7}$. Despite the high incidence of intestinal ascaridiasis in tropical countries, ectopic forms are rare, such as in the appendix, the pancreatic duct, the bile duct or hepatic parenchyma ${ }^{8,9}$.

The chronic illness and age of the patient at first appearance suggested malignancy; nevertheless an ultrasound demonstration of an abscess suggested the possibility of an associated bacterial or parasitic disease which was confirmed by direct examination and cytological study. Presence of both unfertilized egg and migrating larvae suggest that this person might have been repeatedly infected by this parasite which may be called as visceral Larva migrans. And also an adult worm might have been located in the liver parenchyma. In the case reported by Velho PE et al. and the patient was found to have intestinal ascariasis along with nematode larvae which they identified as Ascaris lumbricoides in the lesions of the liver $^{10}$. Intestinal ascariasis is also found in our case. As Bangladesh is a developing country and is situated in tropical zone, Parasitic infestation is a common entity here among the rural peoples and Liver abscess is also seen quite often ${ }^{12,13}$. Parasitic liver abscesses are mostly caused by Entamaeba Histolytica. Ascaris in Liver has though very rarely been reported so far, it may not be unusual to get some sporadic cases of this ectopic presentation of Hepatic ascariasis in our country.

\section{References}

1. Fogaka H S, Oliveira C S, Barbosa H T, Lanfredi R M \& Chagas V - Liver pseudotumor : a rare manifestation of hepatic granulomata caused by Ascaris lumbricoides ova. Am J Gastroenterol 2000; 95: 2099-2101.

2. Holcombe C-Surgical emergencies in tropical gastroenterology. Gut 1995; 36: 9-11.

3. Blanco Q F, Novella A B, Sanchez M P \& Sanz S J Descriptive

4. Study of 39 cases of hepatic abscess of pyogenic and amebic origin. An Med internat

5. $1995 ; 12: 477-484$

6. 4. Shuichi A, Masumoto A, Unoki H et al. -Transient multiple hepatic nodules

7. with marked infiltration of eosinophils caused by ascariasis. Am J Gastroenterol 1997; 92: 897-898.

8. Mcdonald K L \& Davani M -The rim in hepatic abscess: case report and review of the literature. J nucl Med 1997; 38: 1282-1283.

9. Pinilla A.E., Lopez M C, Ricaurte O et al. - Liver abscess caused by Ascaris lumbricoides: case report. Rev Inst Med trop S Paulo 2001; 43 (6): 343-346.

10. Mischinger H J, Hauser H, Rabl H et al.- Pyogenic liver abscess: studies of therapy and analysis of risk factors. Wld J Surg 1999; 18: 852-858.

11. Khuroo M S-Ascariasis. Gastroenterol Clin N Am 1997; 25: 553-577.

12. Severen M V, Lengele B, Dureuil J, Shapira M \& Dive C H - Hepatic ascaridiasis. Endoscopy 1987; 19: 140-142.

13. Velho P E, Faria AV, Cintra ML, de Souza E M, de Moraes A M. Larva migrans: A case report and review. Rev Inst med Trop S Paulo 2003; 45: 167-171. 